\title{
The Uptake of Radiophosphate by Barley Plants as Influenced by Magnesium
}

\author{
O. J. CROCOMO e E. MALAVOLTA
}

\author{
Centro Nacional de Energia Nuclear na Agricultura \\ Escola Superior de Agricultura "Luiz de Queiroz" \\ Universidade de São Paulo \\ Piracicaba, S. Paulo, Brasil
}

* This work was supported in part by a grant from Fundação de amparo à Pesquisa do Estado de São Paulo (Brasil). 


\section{INTRODUCTION}

It is well known that root uptake of the phosphate ion is an energy requiring process which occurs against a concentration gradient. From the kinetic studies carried out by HAGEN et al. (1957) it became apparent that the limiting factor in the absorption of phosphate by barley roots is represented by a high energy compound which is produced in the process of oxidative phosphorylation. It follows therefore that it is licit to compare the kinetics of phosphorus uptake to that of oxidative phosphorylation as conducted by root mitochondria (see, for details, CROCOMO, 1964). This assumption was proved correct by JACKSON et al (1962): those factors which control the energy storing process in barley root mitochondria have a similar effect in phosphorus uptake; both process show a parallel response to the same inhibitors; it was concluded in addition, that the mitochondria are the particulate seat of the limiting factor in absorption.

Magnesium ion plays a definite role in all process of phosphate transfer including those involved in oxidative phosporylation. Magnesium ion could be, therefore, a limiting factor in phosphate uptake. An old idea exists in the literature through which a role to magnesium is attributed in connection with phosphorus absorption and transfer (see, for instance JACOB \& UEXKÜLL, 1961, p. 56). The present work was undertaken in order to check the correctness of this hypothesis which was made more attractive in face of currente knowledge pointed out previously.

\section{MATERIAL AND METHODS}

Barley seeds were put to germinate according to the technique described by EPSTEIN \& HAGEN (1952). After germinating in the dark the seedlings were grown under diffuse light during 5 days.

Immediately before using some of the seedlings had the root system excised to be used in phosphate uptake studies. Intact seedlings were used to study translocation of absorbed phosphate in the various treatments.

Either one gm portions of excised roots or 6 seedlings were placed in contac with radiophosphate and different con- 
centrations of $\mathrm{MgCl}_{2}$, the total volume being $130 \mathrm{ml}$ (see Table 1). The final concentration of $\mathrm{KH}_{2} \mathrm{P}^{32} \mathrm{O}_{4}$ was in each case $1 \times 10^{-5} \mathrm{M}$. Uptake and translocation were let to take place under continuous aeration for periods ranging from 20 to 120 minutes.

After the various experimental periods the roots were washed with unlabelled $\mathrm{KH}_{2} \mathrm{PO}_{4}$ and with deionised water; both excised roots and the tops of the intact plants were dried and ashed. Countings were made in the hydrochloric acid extracts of the ashes.

TABLE 1

Levels of $\mathrm{MgCl}^{2}$ used in the experiments

\begin{tabular}{cc}
\hline Level & concentration \\
\hline 0 & $1 \times 10^{-5}$ \\
1 & $2 \times 10^{-5}$ \\
3 & $5 \times 10^{-5}$ \\
4 & $1 \times 10^{-4}$ \\
5 & $1 \times 10^{-3}$ \\
6 & 1 \\
7
\end{tabular}

\section{RESULTS AND DISCUSSION}

1. Preliminary study. A preliminary trial was carried out in order to find out the best time for contact with the various solutions to allow for the accumulation of enough activity to be counted with accuracy.

As shown in Tables 2 and 3 both absorption and transiocation of radiophosphorus increased with time. The period of 2 hours of contact was chosen for the remaining experiments; this time not only permits higher amounts of $\mathrm{P}^{32}$ to be absorbed and translocated but also let the differences among treatments to be more marked.

2. Uptake and translocation. Tables 1 and 2 show that raising the level of magnesium ion in the solution causes 
an increase both in uptake and translocation of the phosphate ion. When the concentration of $\mathrm{Mg}$ increased from $2 \times 10^{-5} \mathrm{M}$ to $5 \times 10^{-5} \mathrm{M}$ the uptake of radiophosphorus by excised roots was affected linearly. As far as translocation is concerned, there was, however, a decrease when the lower levels of magnesium in the medium are considered in the experimental period of 2 hours; the corresponding values, notwithstandingly, are much higher than those obtained when magnesium was absent from the medium. This raises the possibility of existing a given concentration of $\mathrm{Mg}$, which may be considered as optimal both for uptake and translocation. This assumption was proved to be correct, as shown in Tables 4 and 5 in which the duration of the experiment was 2 hours.

As seen in Tables 4 and 5 , magnesium concentrations higher than $10^{-4} \mathbf{M}$ caused a decrease both in uptake and translocation of the phosphorus applied. When the magnesium level in the medium was raised above $10^{-4} \mathrm{M}$ there was an inhibitory effect in uptake and translocation. These data plus those contained in Tables 2 and 3 permit to conclude that both uptake and translocation occur at maximum rates in the concentration interval between $5 \times 10^{-5} \mathrm{M}$ and $10^{-4} \mathrm{M}$; since the results corresponding to the latter are lower, it appears that under the experimental conditions, $5 \times 10^{-5} \mathrm{M}$ should be considered as an optimum.

The nature of the inhibitory effect shown at higher magnesium concentrations cannot be explained at this moment. It could be due. for instance, to a mere precipitation of an insoluble magnesium phosphate at the root surface. This idea is supported by the fact that inhibition does occur when the magnesium concentration exceeds the phosphate ion concentration in the medium. Experiments under way are aimed to solve this question. 


\section{TABLE 2}

Absorption of radiophosphorus by excised barley roots as influenced by magnesium concentration.

\begin{tabular}{ccc}
\hline $\begin{array}{c}\text { Time } \\
\text { (minutes) }\end{array}$ & $\begin{array}{c}\text { Final } \mathrm{Mg} \\
\text { concentration }(\mathrm{M})\end{array}$ & c.p.m P32/mg ash (*) \\
\hline 20 & 0 & 307 \\
20 & $1 \times 10-5$ & 503 \\
20 & $2 \times 10-5$ & 535 \\
20 & $5 \times 10-5$ & 578 \\
40 & 50 & 405 \\
40 & $1 \times 10-5$ & 518 \\
40 & $2 \times 10-5$ & 841 \\
40 & $5 \times 10-5$ & 937 \\
120 & 50 & 1148 \\
120 & $1 \times 10-5$ & 2023 \\
120 & $2 \times 10-5$ & 2311 \\
120 & $5 \times 10-5$ & 2400 \\
\hline
\end{tabular}

(*) average of 9 replicates.

\section{TABLE 3}

Translocation of radiophosphorus into the aereal portion of barley seedlings as influenced by the magnesium concentration in the root medium.

\begin{tabular}{|c|c|c|}
\hline $\begin{array}{c}\text { Time } \\
\text { (minutes) }\end{array}$ & $\begin{array}{c}\text { Final Mg } \\
\text { concentration (M) }\end{array}$ & c.p.m $\mathrm{P}^{32} / \mathrm{mg}$ ash $(*)$ \\
\hline 20 & 0 & 19 \\
\hline 20 & $1 \times 10^{-5}$ & 128 \\
\hline 20 & $2 \times 10^{-5}$ & 130 \\
\hline 20 & $5 \times 10^{-5}$ & 150 \\
\hline 40 & 0 & 54 \\
\hline 40 & $1 \times 10-5$ & 223 \\
\hline 40 & $2 \times 10-5$ & 244 \\
\hline 40 & $5 \times 10^{-5}$ & 250 \\
\hline 120 & 0 & 67 \\
\hline 120 & $1 \times 10-5$ & 167 \\
\hline 120 & $2 \times 10-5$ & 190 \\
\hline 120 & $5 \times 10^{-5}$ & 305 \\
\hline
\end{tabular}

(*) average of 9 replicates. 


\section{TABLE 4}

Uptake of radiophosphorus by excised barley roots, 2 hours of contact.

\begin{tabular}{cc} 
Magnesium & \\
concentration $(\mathrm{M})$ & c.p.m. P32 $/ \mathrm{mg} \mathrm{ash}\left(^{*}\right)$ \\
0 & 618 \\
$10^{-4}$ & 1000 \\
$10^{-3}$ & 657 \\
1 & 298 \\
2 & 130 \\
\hline
\end{tabular}

(*) average of 9 replicates.

TABLE 5

Translocation of radiophosphorus into the aereal portion of barley seedlings, 2 hours of contact.

\begin{tabular}{cc} 
Magnesium & \\
concentration $(M)$ & c.p.m. P32 $/ \mathrm{mg}$ ash (*) \\
0 & 125 \\
$10-4$ & 146 \\
$10-3$ & 129 \\
1 & 36 \\
2 & 12 \\
\hline
\end{tabular}

(*) average of 9 replicates.

\section{SUMMARY AND CONCLUSIONS}

The uptake and translocation of phosphorus-P32 $(1 \times$ $\left.10^{-5} \mathrm{M}\right)$ by excised barley roots, and barley seedlings, respectively, as a function of various concentrations of magnesium $\left(0,10^{-5}, 2 \times 10^{-5}, 5 \times 10^{-5}, 10^{-4}, 10^{-3}, 1\right.$ and 2 , in molarity) was studied in the experiment described herein. In both cases, the seedlings were of the same age ( 3 to 5 days old.) Within 
the experimental conditions, the following conclusions were drawn:

1. The best experimental period was 2 hours;

2. The magnesium level that is favorable to the accumulation and translocation of radiophosphorus is $5 \times 10^{-5} \mathrm{M}$;

3. In the presence of higher concentrations of magnesium the uptake of radiophosphorus was lower, and in the presence of $1 \mathrm{M}$ and $2 \mathrm{M}$ it was almost inhibited. However, the nature of that inhibition was not established, being the subject of future work.

\section{LITERATURE CITED}

CROCOMO, O.J., 1964. Sôbre a absorção de fósforo pelas raízes de plantas. Semin. Depto. de Química, ESALQ, mimeogr.

EPSTEIN, E. and C. E. HAGEN. $1952 \mathrm{~A}$ kinetic study of absorption of alkali by barley roots. Plant Physiol. 27: 457-474.

HAGEN, C.E., J.E. LEGETT and P.C. JACKSON. 1957 The sites of orthophosphate uptake by barley roots. Proc. Natl. Acad. Sci. 43: 496-506.

JACKSON, P.C., S.B. HENDRICKS and B.M. VASTA. 1962 Phosphorylation by barley roots mitochondria \& Phosphate absorption by barley roots. Plant Physiol. 37:8-17.

JACOB, A. and $H$. von UEXKULL. 1961 Fertilización, Internationale Handelmaatschappij voor Meststoffen N.V., Amsterdam. 
